\title{
Rhizobium-Legume Symbiosis: Molecular Determinants and Geospecificity
}

\author{
Pavan Kumar Pindi* (D), Sadam D.V. Satyanarayana $(\mathbb{D}$ and K. Sanjeev Kumar \\ Department of Microbiology, Palamuru University, Mahabubnagar - 509 001, Telangana, India.
}

\begin{abstract}
Symbiosis in legume plants is an ever evolving research as the factors that initiate, regulate and accomplish the complex relationship between the plant and microorganisms are very dynamic. Rhizobium is a common symbiont in legumes which throughout the process of evolution, has undergone multiple phenotypic and genotypic manifestations. Crop specificity based on the compatible combination of plant and rhizobium is, of course, the modern concept in advanced biofertilizer research. Yet, the biofertilizers are not being considered as replacement of synthetic fertilizers, but just an alternative to the chemical fertilizers. It is clearly evident from both the usage and yielding perspectives that biofertilizers are not the priority of the farming communities. A serious fundamental amendment in the research of biofertilizers is proposed in this review article in the name of Geo specificity. Exploring the natural combination of rhizobium and legume plants with respect to geography and reinoculating in the same geographical region is the central dogma of the concept. Rhizobium of one geography could be sensitive to other geographies even though the crop remains the same. Therefore a new consideration in the biofertilizer research is proposed, presented and illustrated in this review to give more insights about Bio-Geo Specificity.
\end{abstract}

Keywords: Rhizobium, symbiosis, Geospecificity, legume plants

*Correspondence: pavankumarpindi@gmail.com; 91-9849327029

(Received: December 28, 2019; accepted: February 21, 2020)

Citation: Pindi PK, Satyanarayana SDV, Kumar KS. Rhizobium-Legume Symbiosis: Molecular Determinants and Geospecificity. J Pure Appl Microbiol. 2020;14(2):1107-1114. doi: 10.22207/JPAM.14.2.04

(C) The Author(s) 2020. Open Access. This article is distributed under the terms of the Creative Commons Attribution 4.0 International License which permits unrestricted use, sharing, distribution, and reproduction in any medium, provided you give appropriate credit to the original author(s) and the source, provide a link to the Creative Commons license, and indicate if changes were made. 


\section{INTRODUCTION}

Plant interacting microbes vary in the nature of the relationship they establish with their hosts. For example, pathogenic microorganisms establish interactions that can severely impair the development/survival of the susceptible hosts. In distinction to pathogenic bacteria, symbiotic bacteria example; rhizobia are beneficial to their hosts. Rhizobia, the soil bacteria interact symbiotically with the leguminous plants forming nitrogen-fixing nodules ${ }^{1}$. The process initiates on the root, beginning with the exchange of signal molecules between the host and microbe ${ }^{2}$. It then invades the plant by forming infection threads. Initiation begins from the curled root hair ends and grows towards the plant cortex ${ }^{3}$. Located just in front of these growing threads are the inner cortical cells. Dedifferentiation of these cells leads to the induction of primordium of the nodule. Further, the activity of the nodule meristem is initiated on the outer side of the primordium leading to the further growth of the nodule ${ }^{4}$.

The process of nitrogen fixation occurs naturally by which the atmospheric nitrogen is converted into ammonia (readily available form for plants) with the help of the nitrogenase enzyme ${ }^{5}$. The bacteria present inside the nodules help to fix this nitrogen and the process results in a complex interaction between the host plant and the rhizobia. This mutualism has found to be advantageous for both the host; in which plants provide rhizobacteria with carbon as a source and energy that is necessary for its growth and functions and the microbes, in turn, provide reduced nitrogen to the host in the form of ammonium ${ }^{6}$. This process of nodulation and nitrogen fixing requires several rhizobia bacteria as well as symbiotic genes for effective symbiosis between the host and the microbes. Rhizobial genes present in rhizobacteria will play an important role in nodule development and bacterioid metabolism. Some of them, "nod, nol, noe" genes involves in nodulation, "nif, fix" for nitrogen fixation, and the other plant genes that are expressed in the root tissue are nodulin genes ${ }^{7}$.

One conspicuous feature of legumerhizobialsymbios is a highly specific feature that may occur both at initial and final stages like bacterial infection and nitrogen fixation respectively.
Domesticated crop species were found to have higher specificity i.e. fewer compatible symbionts than their wild counterparts ${ }^{8}$. Such constraints could decrease the yield in conditions where no favorable strains are available. This knowledge concerning genetic control of symbiotic specificity would help manipulate the key genetic factors controlling the interaction and improve the agronomic potential of the root nodule symbiosis. Hence the present review will give a brief overview of the various factors accounting for this to the symbiotic specificity and prove that nodules occupy a competitive niche for microbial accommodation.

\section{Review}

\section{Flavonoid-NodD interaction}

In the early course of legume-rhizobial symbiosis, the legumes produce flavonoids, which diffuse across the bacterial membrane resulting in the activation of nodulation genes (nod). These genes encode enzymes that produce bacterial Nod factors, thereby initiating a symbiotic development for the most part of leguminous plants ${ }^{9}$. Once symbiosis is initiated, the process of transcription occurs furthering this mutualism. Flavonoid activates bacterial proteins (NodD) belongs to the LysR family of transcription regulators mediate this transcription of nod genes. These NodD genes bind to the nod boxes (DNA motifs), which are found in the nod genes promoter region ${ }^{10}$.

Broughton and Peck, et al. demonstrated that these NodDs from rhizobial groups respond differently to different flavonoids ${ }^{11,12}$. In view of the fact that legumes produce various types of flavonoids, nod genes that are regulated by NodD will respond to the specific flavonoids at an early stage of symbiosis. For example, mutations in the nodD from $R$. leguminosarumbv. trifoli results host range extension owing to the expression of nod genes with flavonoid inducers that are generally dormant in nature ${ }^{13}$.The role of NodD regulation by nodD gene expression of Sinorhizobiummeliloti and the mutated expression of nodD of $S$. meliloti was explained in Peck et al..$^{12}$ research. It is henceforth established that flavonoid induced nod gene expression depends on the source of NodD.

\section{Determinants of specificity}

\section{Nod factors}

The process of nodulation in most part of the legume plants occurs by producing Nod 
factors. In contrast, photosynthetic bacteria nodulate without producing Nod factors, the reason being the absence of Nod genes ${ }^{14}$. The Nod factors possess a backbone structure called $\mathrm{N}$-acetyl glucosamine oligosaccharide with a fatty chain at the non reducing end which is similar in different rhizobia but vary in size and saturation, including supplementary additions at each ends, such as glycosylation and sulfation ${ }^{15}$. These modifications help us to determine if a particular Nod factor be able to perceive by a particular host $^{16}$.

The nodABC genes usually present in all rhizobium bacteria required for the synthesis of Nod factors (NF's) which are made up of lipo-chitooligosaccharides. A mutation occurs in nodABC genes that interrupt and abolish the entire process of symbiosis. Apart from this, any modifications in the additional genes that determine the Nod factor corealters this specificity. For instance, obliterating the nodE gene present in R. leguminosarum bv. trifolii changes the uniqueness of the fatty acyl chain attached to the Nod factor and this modification affects symbiosis with Trifolium species ${ }^{17}$.

Perception of signals from the Nod factor is mediated by NFRs i.e. Nod factor signals. They are basically serine/threonine receptor kinases containing LysM motifs in the extracellular component ${ }^{18}$. These motifs were demonstrated by molecular and genetic analyses in L. japonicas as host determinants of symbiosis specificity. It was observed that by transferring Lj-NFR1 and Lj-NFR5 receptors into a legume $M$. truncatula have enabled nodulation by a Mesorhizobium lotisymbiont in the L. japonicus legume plant ${ }^{19}$.

Rhizobial surface polysaccharides \& plant lectins Added classes of bacterial components that are the key factors to interact with the host include the bacterial surface polysaccharides, reported in numerous studies as having a symbiotic role. A various group of bacterial polysaccharides such as lipopolysaccharides (LPS), cyclic glucans, Exopolysaccharides (EPS), and capsular polysaccharides is the bacterial groups of polysaccharides that interact with the host and any defect in any of these components results in the immediate failure of the early or later stages of symbiosis. It was noticed that defects in the EPS production resulted in the arrest at the infection thread stage in the S. meliloti group of microorganisms ${ }^{20,21}$. Furthermore, the severity of these defects had a correlation with the degree of change in the structure of EPS ${ }^{22}$. Likewise, an observed failure in the production or export of cyclic b-glucansled to a drastic problem of infection thread malformation or no formation during symbiosis in the host plant ${ }^{23}$.

Numerous strains of $S$. meliloti distinguished ecotypes of $M$. truncatula by producing a normal nodule on one and defective ones on the other ${ }^{24}$. It was demonstrated from the above-mentioned study that by an exchange of EPS locus the phenotype can be switched, by supporting this concept that the surface polysaccharides are the determinants of specificity in the symbiosis process of legume vs.rhizobium. At the nitrogen fixing level, bacterial polysaccharides specificity was expressed in various other legume-rhizobial interactions. For example, Exopolysaccharides mutants of $M$. Loti produced functional nodules on $L$. pedunculatus and non-functional ones on L. leucocephala ${ }^{25}$. In $R$. leguminosarum strain 3841 where some lipopolysaccharide mutants behaved normally on a pea, whereas other mutants behaved a defective mechanism in nitrogen fixation ${ }^{26}$. Lectins belonging to the family of carbohydrate binding proteins are normally found in the legume seeds. Their role as receptors for rhizobial polysaccharides was speculated long ago and thus acts as a determinant of host range ${ }^{27}$. They bind to the surface polysaccharides and promote the addition of rhizobia to root hairs, consequently, initiating nodule formation by enhancing the delivery of Nod factors towards root hairs ${ }^{28,29}$. An observation says that host specificity depends on the - surface polysaccharides interactions in which lectin genes would support a host range expansion ${ }^{30}$.

\section{Host immunity}

The plant immune system helps fight against any microbial attack by forming structural barriers preventing invasion and subsequent infection. In the initial phases, they respond to the attack by triggering pathogen-associated molecular pattern immunity (PAMP). In order to dampen this immunity and gain to the host access, gram-negative microbes use a type III secretion system (T3SS). Further, as the second line of defense, plant genes perceive the effector 
protein of the invading microbe to initiate effectortriggered immunity ${ }^{31}$. Therefore, microbe-encoded effector and plant defense act as determinants of host range for pathogens.

In the preliminary period of compatible legume-rhizobial interaction, defense responses do occur but become less pronounced as symbiosis is established ${ }^{32}$. Microbe-associated molecular patterns (MAMPs) i.e. nod factors plus surface polysaccharides could have played a possible role in the inhibition of defense responses during compatible legume hosts ${ }^{33-36}$. Contrastingly, these MAMPs can bring for the defense response in nonleguminous plants ${ }^{37}$. This suggests that rhizobia could have developed their specific MAMPs recognized definitive compatible legume hosts for the development of symbiosis.

Infection thread formation initiates when rhizobia get entrapped between the two root hair cells. The number of threads that are initiated with a rhizobial strain generally outnumbers the number of developing nodules ${ }^{38}$. Nutman documentation of infection and nodular dynamics observed that infection proceeds in two phases, First the early phase in which the higher infection rate and the second phase related to the time of nodule formation had a much lower infection rate. He furthermore noticed that the early stage of infections was not uniformly disseminated along the seedling root. There were zones that predominantly susceptible to early infection (root hairs), in which the infection occurred preceding to their occurrence in the farther zone ${ }^{39}$. Apart from these experiments involving split root systems and nodule excision found that nodules accountable for this decline in infection rates ${ }^{(40-43}$. These findings indicate that the plant itself controls its infection rates and, also its numbers of infections to permit the progress of nodule developmental pathways.

\section{Strain-specific nitrogen fixation}

Legume plant naturally builds a fundamental capacity in its nodules to accommodate both the symbiotic as well as endophytic bacteria for their respective roles to perform. However co-inoculation studies revealed that symbiotic bacteria occupy a majority portion of the nodule and the endophytes remained in a small distinctive segment of the nodule ${ }^{44}$. This demonstrates the ability of the symbiont to adopt the nodule environment and compete with the endophytes. It also reveals the fact that symbiotic bacteria effectively perform the communication and improves its mechanical capacity with the host while infecting the rizho zone of the plant. As such no definitive rate of nitrogen fixing efficiency of plant-rhizobial combinations, it varies with a variety of combinations. In some extreme conditions though the rhizobial strains nodulate a host plant but were unable to fix nitrogen. On the other hand, the same strain could have the capacity to fix nitrogen with alternative host genotypes $^{45,46}$.

Recent advances in the literature have led to an increased understanding of the process of nodule development; however, mechanisms involving nitrogen fixation have largely been unknown. But the nodulation specificity and interaction was well understood and published in between the M. truncatula host and S. melilotisps. to achieve the identification of precise genes involved $^{47-49}$. Genetic analysis recognized a distinct gene called "Mt-Sym6" which is a conditioned host specific gene in S. meliloti strain A145 for nitrogen fixation immediately upon inoculation into the host plant ${ }^{45}$. Studies performed on strains of $R$. leguminosarum bv. trifolii found strange results of varying compatibility with white clover plant and caucasian clover plant. One of the $T$. ambiguum rhizobial strains, ICC105 produced non-fixing nodules when inoculated in white clover whereas produced nodulating genes efficiently while inoculated on to the caucasian clover ${ }^{50}$. The above genetic experiments illustrated that non nodulation is because a unique sequence of ICC105 promoter regions prevented nifA protein which is necessary for activating nitrogenase enzyme assembly.

\section{Bio-geo specific rhizobacteria}

The Leguminosae comprising of 19,500 species and 751 genera that were populated major surface portion of land on the earth. Their respective species were adapted all most all terrestrial ecosystems including deserts, tropical rain forests and habituated to tropical as well as arctic habitats ${ }^{51-53}$. A papilionoid tribe having 65 native Fynbos legumes was analyzed with rhizobial diversity and their specific host preferences. For further deep analysis, sequencing of $16 \mathrm{~S}$ rRNA, recA, atp Dchromosomal genes and $\operatorname{nod} A$, nif 
Hsymbiosis related genes recognized and named those Mesorhizobium as alpha symbionts and Burkholderia as a betasymbiont. Though the host genotype was one of the factors influencing rhizobial diversity, environmental factors like the acidic nature of the soil and site elevation showed a positive association with genetic variations in the Mesorhizobium and Burkholderia. These genetic variations demonstrated host and environmental interactions for the distribution of Fynbosrhizobia in various locations ${ }^{54}$.

A study on Australian Acacia with rhizobia interactions was conducted for understanding the geographic patterns of symbiont abundance and adaptation. Among those 58 different sites were characterized like the size of symbiont population, environmental parameters, and soil chemistry. Further better understanding greenhouse soil experiments were conducted with native soils filled in pots, minimal apparent differences were found between host and seeding responses. When another species $A$. salicinagrew in A. stenophylla and $A$. salicinasoils in a similar fashion to check for the same behavior, no similar results were found as $A$. stenophylla yielded. This signifies that the plants of one geography have a broad adaptation to its own rhizosphere bacteria and perform the best symbiotic compatibility. The soil chemistry also plays a prominent role in nodulation and host growth ${ }^{55}$.

Studies conducted to identify the involvement in the segregation and detection of crop specific rhizobium strains for Glycine max, Cicer aritenum, and Arachis hypogaea from Bhadrachalam forest region. One best rhizobia sps. among the 45 soil samples were analyzed with biochemical, physical and in silico parameters and employed to various unfertile soil samples of the same geography showed an improvement in the plant growth and yield when compared to its counterpart control samples. Further phylogenetic analysis of Glycine max, Cicer aritenum, and Arachis hypogaea was revealed that $B$. japonicum, M. ciceri, and R. leguminosarum species respectively supported the plant growth by means of increasing IAA, ACC, and nitrogen compounds as well as increasing the growth and nodulation ${ }^{56-58}$. In silico analysis revealed that nifA protein is the root cause for the activation of nitrogenase enzyme which has a derivative capacity of nitrogen fixing ${ }^{59}$. If found any defect in the nifA protein structure usually could not fix atmospheric nitrogen. Though a deficiency found in the M.ciceri of nifA protein, it could, fortunately,manage to promote the growth and produce a good amount of nitrogen through its missing amino terminal domain. The literature says that the activity of the amino terminal domain of nifA protein is hidden in a few special conditions. Further, these studies said that geographical acclimatization and adaptability could a reason for the greater stability of the nifA protein. It is very important to identify cultivable growth promoting Rhizobium strains for selected legume plants inconfined geography.

\section{CONCLUSION}

The effective symbiosis between rhizobia and legumes depends on the Nod factors, flavonoids, bacterial surface polysaccharides and plant lectins. They are known to play a prominent role and any alterations in their structure alter the host specificity. Nod factors secreted by the rhizobia are synthesized by common nodulation genes specific to the host. Symbiotic nodulation genes could have been identified and used as genetic markers for the determination of host specificity as well as symbiotic diversity. The abundance rhizobacteria in the native soil samples could play a vital role in the nodulation and also act as an indicator of the effect of the rhizobial population towards its symbiotic plant. Understanding the differences in effectiveness and specificity of plant symbiosis with relevant species at multiple special scales greatly influences the evolution and ecology of plant, soil communities. This also potentially increases the cost effectiveness in a better natural environment. Further, the native or indigenous strains isolated from a geographical area are found to be more specific towards the crop in the same geography. A serious need to explore the biofertilizers with more variable specifications like geographical acclimatization to optimize the crop yield by sustaining the efficacy and shelf life in order to reduce the use of chemical fertilizers.

\section{ACKNOWLEDGMENTS}

None. 


\section{CONFLICT OF INTEREST}

The authors declare that there is no conflict of interest.

\section{FUNDING}

None.

\section{AUTHORS' CONTRIBUTION}

SDVS contributed to literature collection, designing and writing the manuscript. PPK was supervised and monitored the review for proper structure and grammatical corrections.

\section{ETHICS STATEMENT}

Not applicable.

\section{DATA AVAILABILITY}

All datasets generated or analyzed during this study are included in the manuscript

\section{REFERENCES}

1. Brewin NJ. Development of the legume root nodule. Ann. Rev, Cell Biol., 1991;7:191-226. https://doi. org/10.1146/annurev.cb.07.110191.001203

2. Fisher RF and Long SR. Rhizobium-plant signal exchange. Nature,1992;357:655-660. https://doi. org $/ 10.1038 / 357655 \mathrm{aO}$

3. Vasse J and Truchet G. The Rhizobium-legume symbiosis: observation of root infection by brightfield microscopy after staining with methylene blue. Planta, 1984; 161: 487-489. https://doi.org/10.1007/ BF00407080

4. Libbenga KR and Harkes PAA. Initial proliferation of cortical cells in the formation of root nodules in Pisumsativum L. Planta, 1973; 114: 7-28. https://doi. org/10.1007/BF00390281

5. Udvardi M, Poole PS. Transport and metabolism in legume-rhizobia symbioses. Annu. Rev. Plant Biol., 2013; 64: 781-805. https://doi.org/10.1146/annurevarplant-050312-120235

6. Van Hameren B, Hayashi S, Gresshoff PM, Ferguson BJ. Advances in the identification of novel factors required in soybean nodulation, a process critical to sustainable agriculture and food security. J. Plant Biol. Soil Health, 2013; $1: 6$

7. Naveen Arora. Plant Microbes Symbiosis: Applied Facets Springer; 2015 Edition. https://doi.org/10.1007/97881-322-2068-8

8. Mutch LA and Young JP. Diversity and specificity of Rhizobium leguminosarumbiovarviciae on wild and cultivated legumes. Mol Ecol., 2004; 13: 2435-2444. https://doi.org/10.1111/j.1365-294X.2004.02259.x

9. Oldroyd GE, Murray JD, Poole PS and Downie JA. The rules of engagement in the legume-rhizobial symbiosis. Annu Rev Genet, 2011; 45: 119-144. https:// doi.org/10.1146/annurev-genet-110410-132549

10. Long SR. Rhizobium symbiosis: nod factors in perspective. Plant Cell, 1996; 8: 1885-1898. https:// doi.org/10.1105/tpc.8.10.1885

11. Broughton WJ, Jabbouri $S$ and Perret $X$. Keys to symbiotic harmony. J Bacteriol., 2000; 182: 5641-5652. https://doi.org/10.1128/JB.182.20.5641-5652.2000

12. Peck MC, Fisher RF and Long SR. Diverse flavonoids stimulate NodD1 binding to nod gene promoters in Sinorhizobiummeliloti. J Bacteriol., 2006; 188: 5417-5427. https://doi.org/10.1128/JB.00376-06

13. Mclver J, Djordjevic MA,Weinman JJ, Bender GL and Rolfe BG. Extension of host range of Rhizobium leguminosarumbv. trifolii caused by point mutations in nodD that result in alterations in regulatory function and recognition of inducer molecules. $\mathrm{Mol}$ Plant Microbe Interact, 1989; 2: 97-106. https://doi. org/10.1094/MPMI-2-097

14. Giraud E, Moulin L, Vallenet D, Barbe V, Cytryn E, Avarre $\mathrm{JC}$, et al. Legumes symbioses: absence of Nod genes in photosynthetic bradyrhizobia. Science, 2007; 316: 1307-1312. https://doi.org/10.1126/science.1139548

15. Long SR. Rhizobium symbiosis: nod factors in perspective. Plant Cell, 1996; 8: 1885-1898. https:// doi.org/10.1105/tpc.8.10.1885

16. Lerouge $P$, Roche $P$, Faucher $C$, Maillet F, Truchet G, Prome JC and Denarie J. Symbiotic host specificity of Rhizobium meliloti is determined by a sulphated and acylated glucosamine oligosaccharide signal. Nature, 1990; 344: 781-784. https://doi. org/10.1038/344781a0

17. Spaink HP, Sheeley DM, van Brussel AA, Glushka J, York WS, Tak T, et al. A novel highly unsaturatedfatty acid moiety of lipo-oligosaccharide signals determines host specificity of Rhizobium. Nature, 1991; 354: 125-130. https://doi.org/10.1038/354125a0

18. Limpens E, Franken C, Smit P, Willemse J, Bisseling $\mathrm{T}$, and Geurts R. LysM domain receptor kinases regulating rhizobial Nod factor-induced infection. Science, 2003; 302:630-633. https://doi.org/10.1126/ science. 1090074

19. Radutoiu S, Madsen LH, Madsen EB, Jurkiewicz A, Fukai E, Quistgaard EM, et al. LysM domains mediate lipochitin-oligosaccharide recognition and $\mathrm{Nfr}$ genes extend the symbiotic host range. EMBO J., 2007; 26: 3923-3935. https://doi.org/10.1038/ sj.emboj.7601826

20. Finan $T M$, Hirsch $A M$, Leigh JA, Johansen $E$, Kuldau GA, Deegan S, et al. Symbiotic mutants of Rhizobium meliloti that uncouple plant from bacterial differentiation. Cell, 1985; 40: 869-877. https://doi. org/10.1016/0092-8674(85)90346-0

21. Leigh JA, Signer ER and Walker GC. Exopolysaccharidedeficient mutants of Rhizobium meliloti that form ineffective nodules. Proc Nat/ Acad Sci USA, 1985; 82: 6231-6235. https://doi.org/10.1073/pnas.82.18.6231

22. Cheng HP and Walker GC. Succinoglycan is required for initiation and elongation of infection threads during nodulation of alfalfa by Rhizobium meliloti. J Bacteriol., 1998; 180: 5183-5191. https://doi.org/10.1128/ JB.180.19.5183-5191.1998

23. Dylan T, lelpi L, Stanfield S, Kashyap L, Douglas C, Yanofsky $\mathrm{M}$, et al. Rhizobium meliloti genes required for nodule development are related to chromosomal 
virulence genes in Agrobacterium tumefaciens. Proc Natl Acad Sci USA, 1986; 83: 4403-4407. https://doi. org/10.1073/pnas.83.12.4403

24. Simsek S, Ojanen-Reuhs T, Stephens SB and Reuhs BL. Strain-ecotype specificity in SinorhizobiummelilotiMedicagotruncatula symbiosis is correlated to succinoglycan oligosaccharide structure. J Bacteriol., 2007; 189: 7733-7740. https://doi.org/10.1128/ JB.00739-07

25. Hotter GS and Scott DB. Exopolysaccharide mutants of Rhizobium loti are fully effective on a determinate nodulating host but are ineffective on an indeterminate nodulating host. J Bacteriol., 1991; 173: 851-859. https://doi.org/10.1128/JB.173.2.851-859.1991

26. Kannenberg EL, Rathbun EA and Brewin NJ. Molecular dissection of structure and function in the lipopolysaccharide of Rhizobium leguminosarum strain 3841 using monoclonal antibodies and genetic analysis. Mol Microbiol., 1992; 6: 2477-2487. https:// doi.org/10.1111/j.1365-2958.1992.tb01424.x

27. Bohlool BB and Schmidt EL. Lectins: a possible basis for specificity in the Rhizobium leguminosarum symbiosis. Science, 1974; 195: 269-271. https://doi.org/10.1126/ science.185.4147.269

28. Van Rhijn P, Fujishige NA, Lim PO and Hirsch AM. Sugarbinding activity of pea lectin enhances heterologous infection of transgenic alfalfa plants by Rhizobium leguminosarumbiovarviciae. Plant Physiol., 2001; 126: 133-144. https://doi.org/10.1104/pp.126.1.133

29. Laus MC, Logman TJ, Lamers GE, Van Brussel AA, Carlson RW and Kijne JW. A novel polar surface polysaccharide from Rhizobium leguminosarum binds host plant lectin. Mol Microbiol, 2006; 59: 1704-1713. https://doi.org/10.1111/j.1365-2958.2006.05057.x

30. De Hoff PL, Brill LM and Hirsch AM. Plant lectins: the ties that bind in root symbiosis and plant defense. Mol Genet Genomics, 2009; 282: 1-15. https://doi. org/10.1007/s00438-009-0460-8

31. Jones JD and Dangl JL. The plant immune system. Nature, 2006; 444: 323-329. https://doi.org/10.1038/ nature05286

32. Lohar DP, Sharopova N, Endre G, Penuela S, Samac D, Town C, et al. Transcript analysis of early nodulation events in Medicagotruncatula. Plant Physiol., 2006; 140: 221-234. https://doi.org/10.1104/ pp.105.070326

33. Shaw SL and Long SR. Nod factor inhibition of reactive oxygen efflux in a host legume. Plant Physiol., 2003; 132: 2196-2204. https://doi.org/10.1104/ pp.103.021113

34. D'Haeze W and Holsters M. Surface polysaccharides enable bacteria to evade plant immunity. Trends Microbiol., 2004; 12: 555-561. https://doi. org/10.1016/j.tim.2004.10.009

35. Tellstrom V, Usadel B, Thimm O, Stitt M, Kuster $\mathrm{H}$ and Niehaus K. The lipopolysaccharide of Sinorhizobiummeliloti suppresses defence-associated gene expression in cell cultures of the host plant Medicagotruncatula. Plant Physiol., 2007; 143: 825-837. https://doi.org/10.1104/pp.106.090985

36. Jones KM, Sharopova N, Lohar DP, Zhang JQ, VandenBosch KA and Walker GC.Differential response of the plant Medicagotruncatula to its symbiontsSinorhizobiummeliloti or an exopolysaccharide-deficient mutant. Proc Natl Acad Sci USA, 2008; 105: 704-709. https://doi.org/10.1073/ pnas. 0709338105

37. Staehelin C, Granado J, Muller J, Wiemken S, Mellor RB, Felix G, et al. Perception of Rhizobium nodulation factors by tomato cells and inactivation by root chitinases. Proc Natl Acad Sci USA, 1994; 91: 21962200. https://doi.org/10.1073/pnas.91.6.2196

38. Vasse J, F de Billy and G Truchet. Abortion of infection during the Rhizobium meliloti-alfalfa sybiotic interaction is accompanied by a hypersensitive reaction. Plant J., 1993; 4: 555-566. https://doi. org/10.1046/j.1365-313X.1993.04030555.x

39. Nutman PS. The relation between root hair infection by Rhizobium and nodulation in Trifolium and Vicia. Proc. R. Soc. London Ser. B., 1962; 156: 122-137. https://doi. org $/ 10.1098 /$ rspb.1962.0032

40. Caetano-Anolles $\mathrm{G}$ and PM Gresshoff. Plant genetic control of nodulation. Annu. Rev. Microbiol., 1991; 45: 345-382. https://doi.org/10.1146/annurev. mi.45.100191.002021

41. Caetano-Anolles G, PA Johshi and PM Gresshoff. Spontaneous nodules induce feedback suppression of nodulation in alfalfa. Planta, 1991; 188: 77-92. https:// doi.org/10.1007/BF00197570

42. Kosslak RM and BB Bohlool. Supression of nodule development on one side of a split root system of soybeans caused by prior inoculaton of the other side. Plant Physiol., 1984; 75: 125-130. https://doi. org/10.1104/pp.75.1.125

43. Nutman PS. Studies on the physiology of nodule formation. III. Experiments on the excision of root-tips and nodules. Ann. Bot., 1952; 16:79-101. https://doi. org/10.1093/oxfordjournals.aob.a083304

44. Zgadzaj R, James EK, Kelly S, Kawaharada Y, de Jonge N, Jensen DB, Madsen LH, Radutoiu S. A Legume Genetic Framework Controls Infection of Nodules by Symbiotic and Endophytic Bacteria. PLoS Genetics, 2015; 11(6): art. no. e1005280. https://doi.org/10.1371/journal. pgen. 1005280

45. Tirichine L, de Billy F and Huguet T. Mtsym, a gene conditioning Sinorhizobium strain-specific nitrogen fixation in Medicagotruncatula. Plant Physiol., 2000; 123: 845-851. https://doi.org/10.1104/pp.123.3.845

46. Simsek S, Ojanen-Reuhs T, Stephens SB and Reuhs BL. Strain-ecotype specificity in SinorhizobiummelilotiMedicagotruncatula symbiosis is correlated to succinoglycan oligosaccharide structure. J Bacteriol., 2007; 189: 7733-7740. https://doi.org/10.1128/ JB.00739-07

47. Snyman CP and Strijdom BW. Symbiotic characteristics of lines and cultivars of Medicagotruncatula inoculated with strains of Rhizobium meliloti. Phytophylatica, 1980; 12: 173-176.

48. Parra-Colmenares A and Kahn ML. Determination of nitrogen fixation effectiveness in selected Medicagotruncatula isolates by measuring nitrogen isotope incorporation into pheophytin. Plant Soil, 2005; 270: 159-168. https://doi.org/10.1007/s11104004-1308-y 
49. Rangin C, Brunel B, Cleyet-Marel JC, Perrineau MM and Bena G. Effects of Medicagotruncatula genetic diversity, rhizobial competition, and strain effectiveness on the diversity of a natural sinorhizobium species community. Appl Environ Microbiol., 2008; 74: 5653-5661. https://doi.org/10.1128/AEM.01107-08

50. Miller SH, Elliot RM, Sullivan JT and Ronson CW. Hostspecific regulation of symbiotic nitrogen fixation in Rhizobium leguminosarumbiovartrifolii. Microbiology, 2007; 153: 3184-3195. https://doi.org/10.1099/ mic.0.2007/006924-0

51. Doyle JJ, Luckow MA. The rest of the iceberg. Legume diversity and evolution in a phylogenetic context. Plant Physiol., 2003; 131: 900-10. https://doi.org/10.1104/ pp.102.018150

52. Lavin M, Herendeen PS, Wojciechowski MF. Evolutionary rates analysis of Leguminosae implicates a rapid diversification of lineages during the Tertiary. Syst Biol.,2005; 54: 575-94. https://doi. org/10.1080/10635150590947131

53 Lewis G, Schrire B, Mackinder B, et al. Legumes of the World. Kew, UK: Royal Botanic Gardens, 2005.

54. Benny Lemaire, Oscar Dlodlo, Samson Chimphango, Charles Stirton, Brian Schrire, James S. Boatwright, Olivier Honnay, Erik Smets, Janet Sprent, Euan K James, Abraham M Muasya. Symbiotic diversity, specificity and distribution of rhizobia in native legumes of the Core Cape Subregion (South Africa), FEMS Microbiology Ecology, 2015; 91(2): 1-17. https://doi. org/10.1093/femsec/fiu024
55. Thrall PH, Slattery JF, Broadhurst LM and Bickford S. Geographic patterns of symbiont abundance and adaptation in native Australian Acacia-rhizobia interactions. Journal of Ecology, 2007; 95: 1110-1122. https://doi.org/10.1111/j.1365-2745.2007.01278.x

56. Satyanarayana SDV, Krishna MSR, Kumar PP. Exploring NaturalCombination For Identification Of Upregulated Nitrogen Fixing Bacteria In GlycineMax: An In Vivo, In Vitro And In Silico Approach. Pak. J. Biotechnol., 2018; 15(2): 459-467.

57. Satyanarayana SDV, Krishna MSR, Kumar PP. Exploring naturalcombination for identification of upregulated nitrogen fixing bacteria specific tochickpea in targeted geography: A physical, biochemical, and in Silico approach. Plant Cell Biotechnology and Molecular Biology., 2018; 19(5-6): 155-169.

58. Satyanarayana SDV, Krishna MSR, Kumar PP. Identification ofupregulated nitrogen fixing bacteria for arachishypogaea by exploring naturalcombination: A physical, biochemical, and in silico approach. Journal of Pure andApplied Microbiology, 2018; 12(1): 73-83. https://doi.org/10.22207/JPAM.12.1.10

59. Satyanarayana SDV, Krishna MSR, Pavan Kumar P, Jeereddy $S$. Insilico structural homology modeling of nifA protein of rhizobial strains in selectivelegume plantsInsilico structural homology modeling of nif A protein. Journal ofGenetic Engineering and Biotechnology., 2018; 16(2): 731-737. https://doi. org/10.1016/j.jgeb.2018.06.006 